\title{
EFFECT OF THE GRAIN SHAPE ON THE ELASTIC CONSTANTS OF POLYCRYSTALLINE MATERIALS
}

\author{
H. KIEWEL ${ }^{1}$, H. J. BUNGE ${ }^{2}$ and L. FRITSCHE \\ ${ }^{1}$ Institute of Theoretical Physics B, ${ }^{2}$ Department of Physical Metallurgy, \\ Technical University Clausthal, Germany
}

(Received 20 September 1995)

\begin{abstract}
We examine the influence of the grain shape on the effective elastic moduli of polycrystalline materials. For that purpose the real material is simulated by a cluster of Wigner-Seitz cells. For clarity each aggregate consists of grains with only one type of shape. Therefore we can classify each cluster by the coordination number of its grains. To determine the elastic moduli a homogeneous deformation is subjected to the surface of the cluster. The solution of this boundary value problem yields the average stress and strain governing inside the material whose interconnection by Hooke's law leads to the soughtfor effective constants.
\end{abstract}

The most important result is that with increasing coordination number the elastic moduli decrease.

KEY WORDS: Grain shape, effective elastic constants, cluster method.

\section{INTRODUCTION}

The determination of effective elastic moduli of polycrystalline materials from their microscopic structure presents a very exacting problem. First models to solve this problem were developed by Voigt (1910) and Reuss (1929). They assume that throughout the whole material the strain and stress, respectively, are constant. Although these models are in far contrast with experimental facts, their essential importance consists in yielding upper and lower bounds for the effective elastic constants (Hill, 1952). If there is no information about the microstructure available except for the single crystal moduli and the Orientation Distribution Function (ODF) of the material they are the closest bounds (Kröner 1977). An improvement of these bounds can be achieved if there is no correlation between the elastic moduli of neighboring grains. Then the values of Hashin and Shtrikman $(1962 a, b)$ yield best bounds. If one introduces correlation effects of higher order into the calculation the bounds become even closer. For a systematic treatment see Zeller and Dederichs (1973) and Kröner (1977).

Altogether the latter methods are suitable to limit the elastic moduli for different orders of correlation but they require an enormous mathematical effort to resolve the effect of the grain shape on the effective constants. For that reason we make use of the cluster method by Kiewel and Fritsche (1994a, 1994b) which includes the grain shape explicitly into the calculation and is therefore the appropriate method for our investigations. 


\section{METHOD}

To gain access to the effective constants for different grain shapes we apply the cluster approach which is intensively described by Kiewel and Fritsche (1994b). An aggregate of single crystals is subjected to a homogeneous deformation at its entire surface. By solving this boundary value problem under the constraint that displacement and stress are continuous at the grain boundaries the deformation field inside the material is calculated. The stress-strain relation of the macroscopically homogeneous sample yields then the effective elastic moduli of the material.

\section{RESULTS AND DISCUSSION}

To clarify the influence of the grain shape on the effective elastic moduli we only investigate macroscopically isotropic and homogeneous materials. The orientation of the lattice for different grains should be completely uncorrelated. Each cluster is composed of single crystals of only one type of shape. To fill out the whole space and to avoid overlapping we choose Wigner-Seitz cells to simulate the grains.

The shape of the cluster is approximately spherical since the grains are arranged in shells; i.e. our construction scheme of the aggregate starts with one grain in the origin which is surrounded by nearest neighbors, next nearest neighbors, and so on. The first kind of cluster consists of 201 Wigner-Seitz cells of a face centered cubic (fcc) lattice, the second one of 181 cells of a body centered cubic (bcc) lattice and the third one of 365 cells of a simple cubic (sc) lattice which are ordinary cubes. These particular numbers of cells are based on the arrangement in shells.

For some materials, especially for graphite, there is a wide spread of the experimental values for the single crystal data. We therefore display the employed single crystal stiffnesses in Tables 1 to 3 . To value the order of the effect of the grain shape on

Table 1 Single crystal values for the stiffnesses $c_{i j}$ of the examined cubic materials in GPa

\begin{tabular}{lllll}
\hline & $c_{11}$ & $c_{12}$ & $c_{44}$ & \\
\hline $\mathrm{Ag}$ & 123 & 92 & 45.3 & (Landolt-Börnstein, 1979) \\
$\mathrm{Cu}$ & 169.05 & 121.93 & 75.50 & (Bradfield, 1962) \\
$\mathrm{Fe}$ & 230 & 135 & 117 & (Landolt-Börnstein, 1979) \\
\hline
\end{tabular}

Table 2 Single crystal values for the stiffnesses of the examined hexagonal materials in GPa

\begin{tabular}{lcccccl}
\hline & $c_{11}$ & $c_{12}$ & $c_{13}$ & $c_{33}$ & $c_{44}$ & \\
\hline $\mathrm{Ti}$ & 162.92 & 93.43 & 62.0 & 180.28 & 46.59 & (Bradfield, 1962) \\
$\mathrm{Zn}$ & 161 & 34.2 & 50.1 & 66 & 40 & (Bradfield, 1962) \\
Graphite & 1060 & 180 & 15 & 36.5 & 4 & (Landolt-Börnstein, 1979) \\
\hline
\end{tabular}

Table 3 Single crystal values for the stiffnesses of tin metal in GPa

\begin{tabular}{lccccccl}
\hline & $c_{11}$ & $c_{12}$ & $c_{13}$ & $c_{33}$ & $c_{44}$ & $c_{66}$ & \\
\hline $\mathrm{Sn}$ & 73.2 & 59.8 & 39.1 & 90.6 & 21.9 & 23.8 & (Landolt-Börnstein, 1979) \\
\hline
\end{tabular}


Table 4 Anisotropies for the single crystals of the investigated materials

\begin{tabular}{lcc}
\hline & $A_{G}$ & $A_{E}$ \\
\hline $\mathrm{Ag}$ & 2.923 & 2.675 \\
$\mathrm{Cu}$ & 3.205 & 2.864 \\
$\mathrm{Fe}$ & 2.463 & 2.186 \\
$\mathrm{Ti}$ & 1.483 & 1.433 \\
$\mathrm{Zn}$ & 2.898 & 3.125 \\
$\mathrm{Graphite}$ & 110.00 & 72.07 \\
$\mathrm{Sn}$ & 3.552 & 2.863 \\
\hline
\end{tabular}

the effective elastic constants we have additionally listed in Table 4 the anisotropies of the single crystals $A_{G}$ and $A_{E}$ which are defined by:

$$
A_{G} \stackrel{\text { def }}{=} \frac{G_{\max }}{G_{\min }}
$$

and

$$
A_{E} \stackrel{\text { def }}{=} \frac{E_{\max }}{E_{\min }} .
$$

The extrema of the shear modulus $G$ and of Young's modulus $E$ which are labeled by the indices $\max$ and $\min$ are taken over all crystal directions. The anisotropy $A_{G}$ is identical to the well-known Zener anisotropy or its reciprocal value.

For each material and any type of grain shape we have constructed 10 different sets of random orientations of the crystal lattice inside the grains. The values for the effective moduli of each cluster are recorded in Figures 1 to 7 . The arithmetic mean and the pertinent standard deviation of these moduli are displayed in Tables 5 to 7 . To test the reliability of our approach we have determined the values of Reuss and Voigt, which are identical to the bounds of Hill. For any grain shape and for any kind of correlation between different grains the moduli of the polycrystalline materials have to fall within these bounds. Without any exception this requirement is fulfilled. Additionally we have calculated the bounds of Hashin and Shtrikman (1962a, b) which are only valid if there is no correlation between the elastic moduli of neighboring volume elements. The aggregates used for our investigations fulfill this supposition only approximately since the small number of grains (in the sense of statistics) causes a relatively large grain size compared with the size of the entire cluster. For that reason the latter bounds can merely serve as indicators for serious systematic errors. Nearly all moduli fall within these bounds. The maximum deviation is about $1 \%$ in the case of iron for the fcccluster, which is in the range of the expected statistical accuracy. The bulk modulus for the cubic materials is an invariant measure. As a consequence the values of Reuss and Voigt are identical and can serve as a criterion to test the accuracy of our extensive calculations (Table 5). As has to be, the cluster approach yields in this case exactly the values of Reuss and Voigt. If the microstructure of the investigated material is completely uncorrelated the values of Kröner (Kröner, 1958; Kneer, 1964; Kneer, 1965) present the exact effective moduli. They are also reported in Tables 5 to 7 . 
1(a)

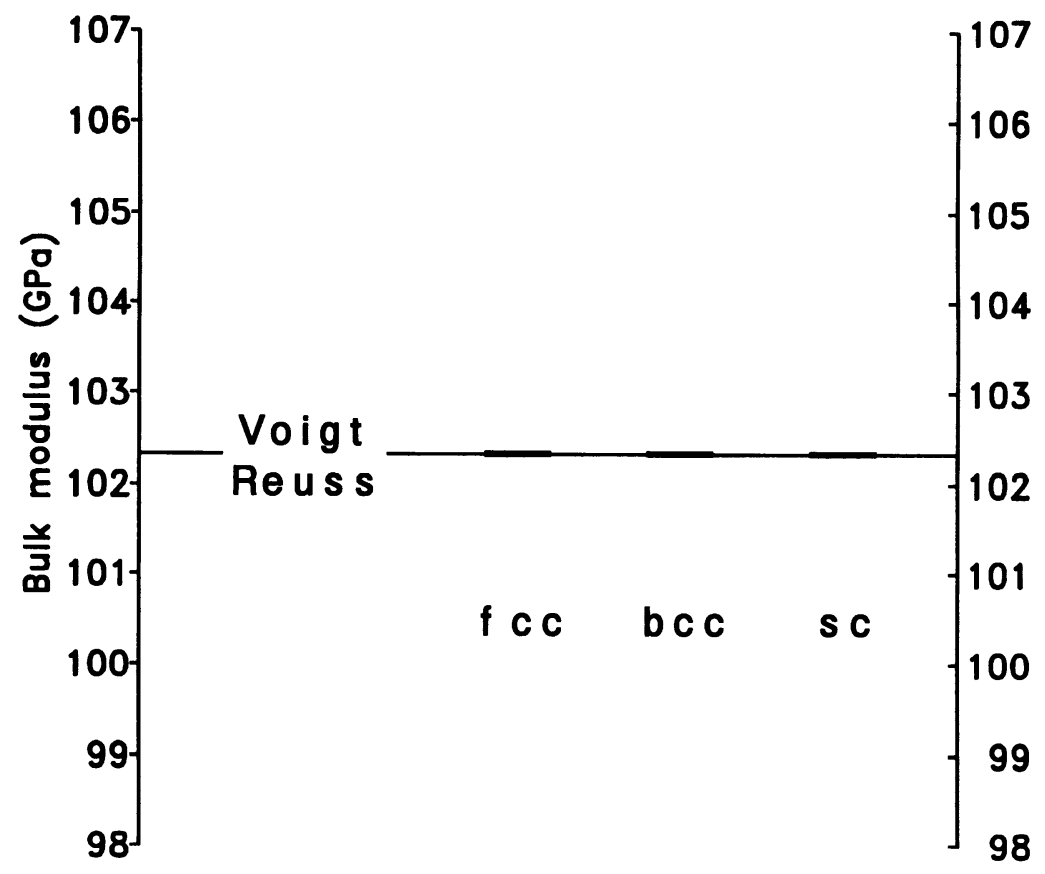

1(b)

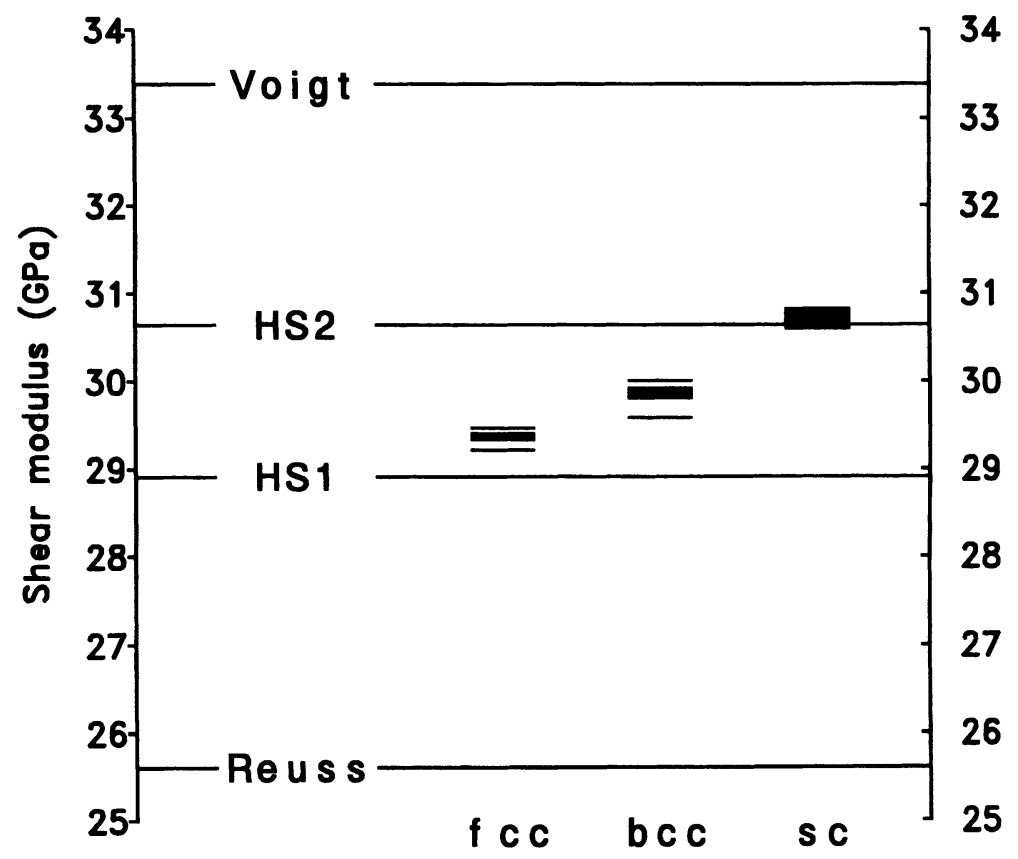

Figure 1 The elastic moduli of macroscopically isotropic silver metal in GPa. We label the bounds of Hill by Reuss and Voigt. The symbols HS1 and HS2 stand for the lower and upper bounds of Hashin and Shtrikman (1962a, b), respectively. For every type of grain shape we have chosen 10 different sets of random orientations of the crystal lattice inside the grains. The results for every set are displayed by a short bar. We sign the different grain shapes by the common abbreviations for the Wigner-Seitz cells constituting the cluster: sc (simple cubic), bcc (body centered cubic), fcc (face centered cubic). 
1(c)

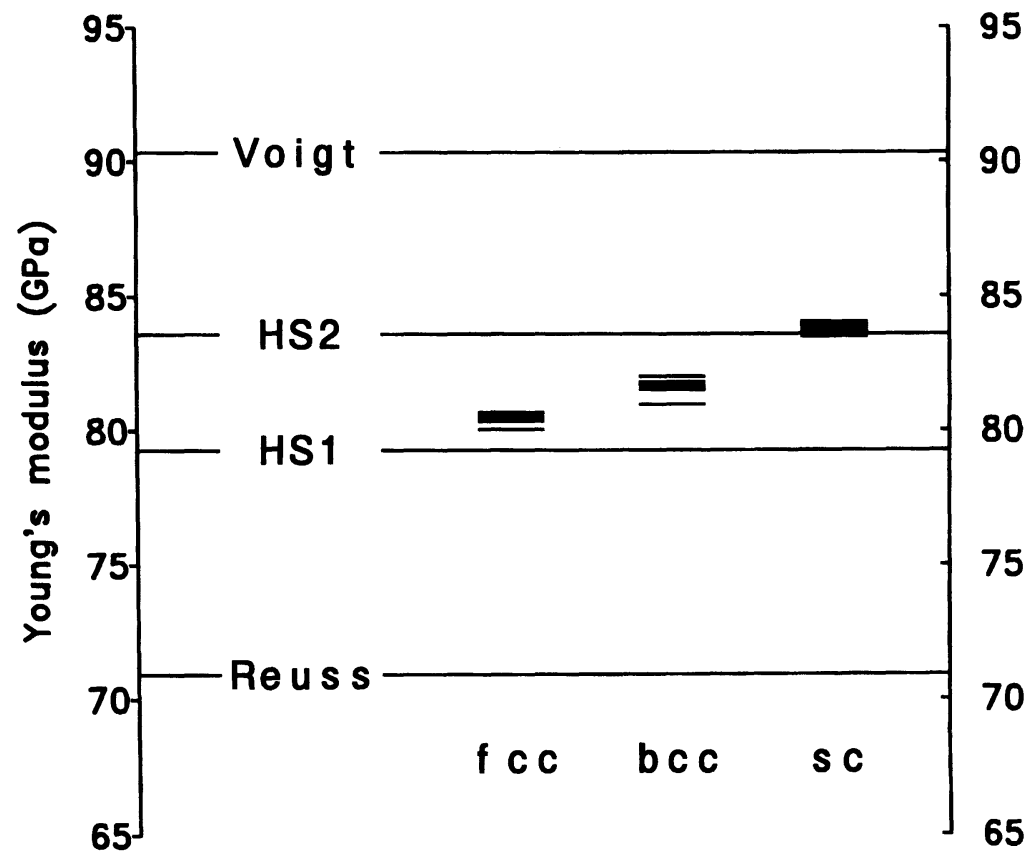

Figure 1 The elastic moduli of macroscopically isotropic silver metal in GPa. We label the bounds of Hill by Reuss and Voigt. The symbols HS1 and HS2 stand for the lower and upper bounds of Hashin and Shtrikman (1962a, b), respectively. For every type of grain shape we have chosen 10 different sets of random orientations of the crystal lattice inside the grains. The results for every set are displayed by a short bar. We sign the different grain shapes by the common abbreviations for the Wigner-Seitz cells constituting the cluster: sc (simple cubic), bcc (body centered cubic), fcc (face centered cubic).

2(a)

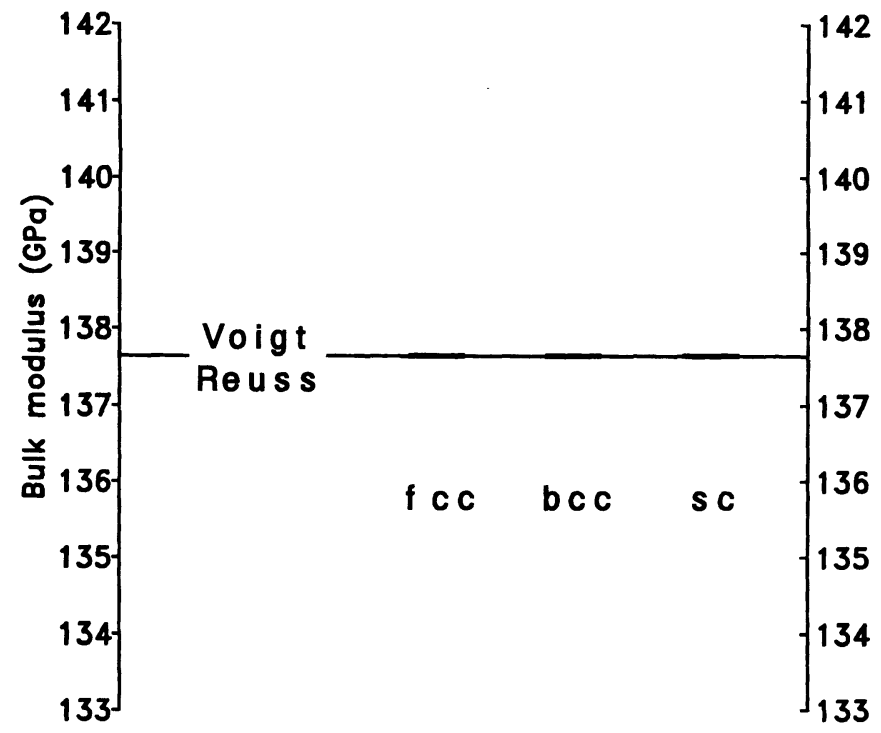

Figure 2 The elastic moduli of macroscopically isotropic copper metal in GPa. The situation is the same as in Figure 1. 
2(b)

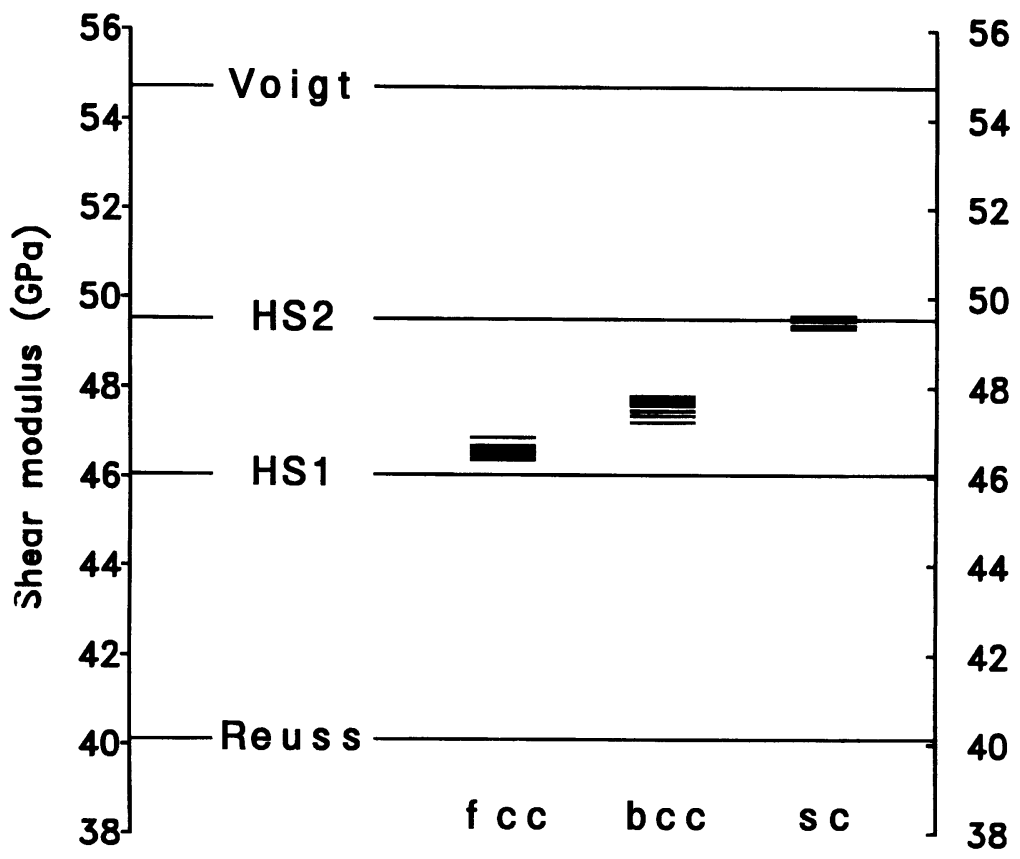

2(c)

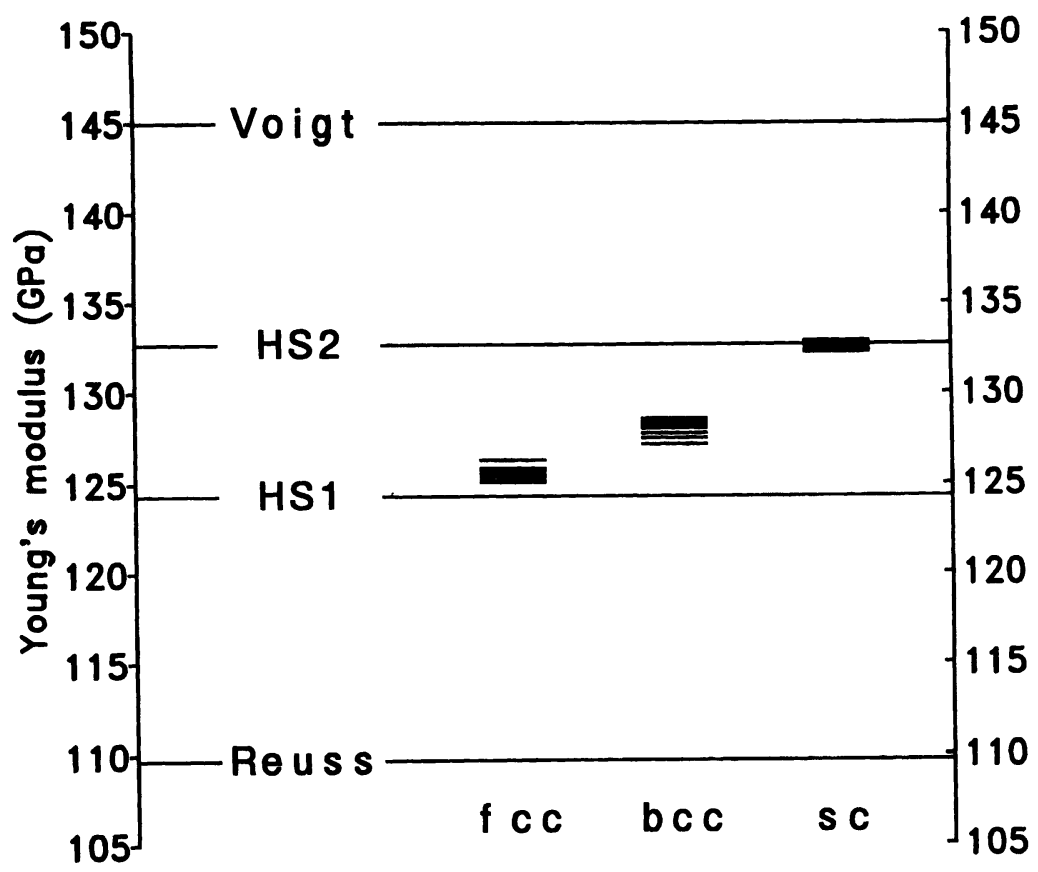

Figure 2 The elastic moduli of macroscopically isotropic copper metal in GPa. The situation is the same as in Figure 1. 
EFFECT OF THE GRAIN SHAPE

3(a)
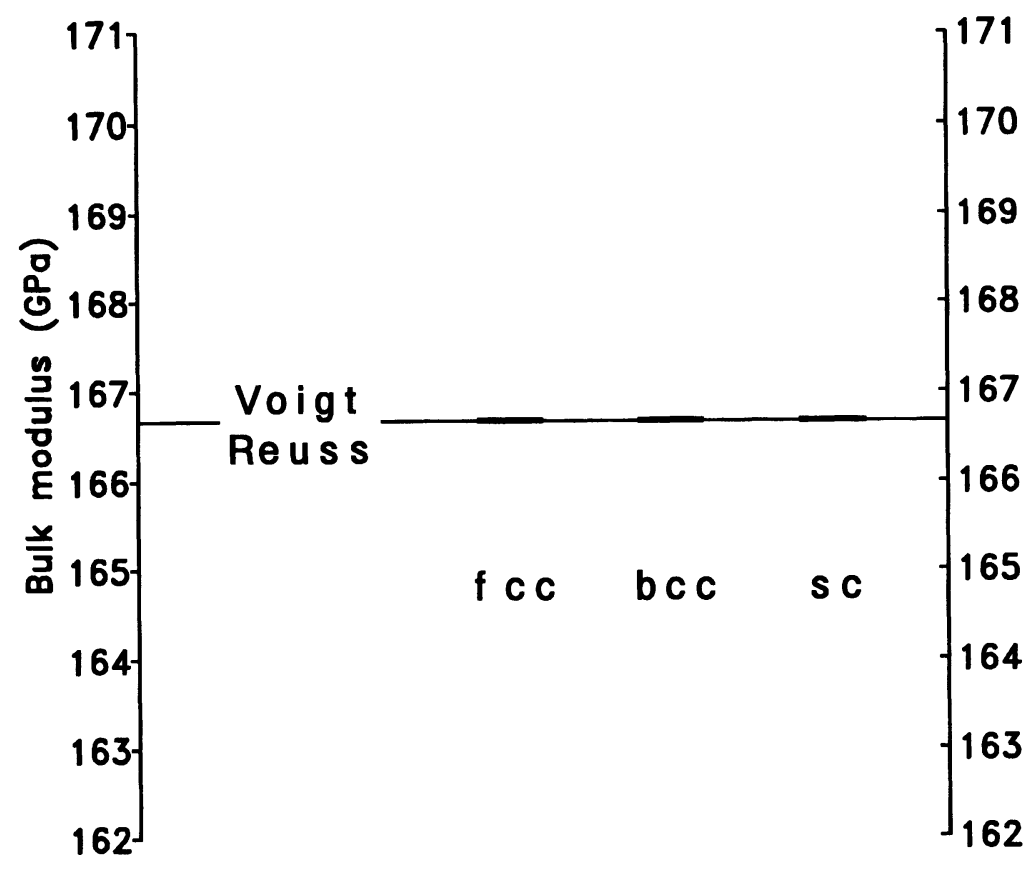

3(b)

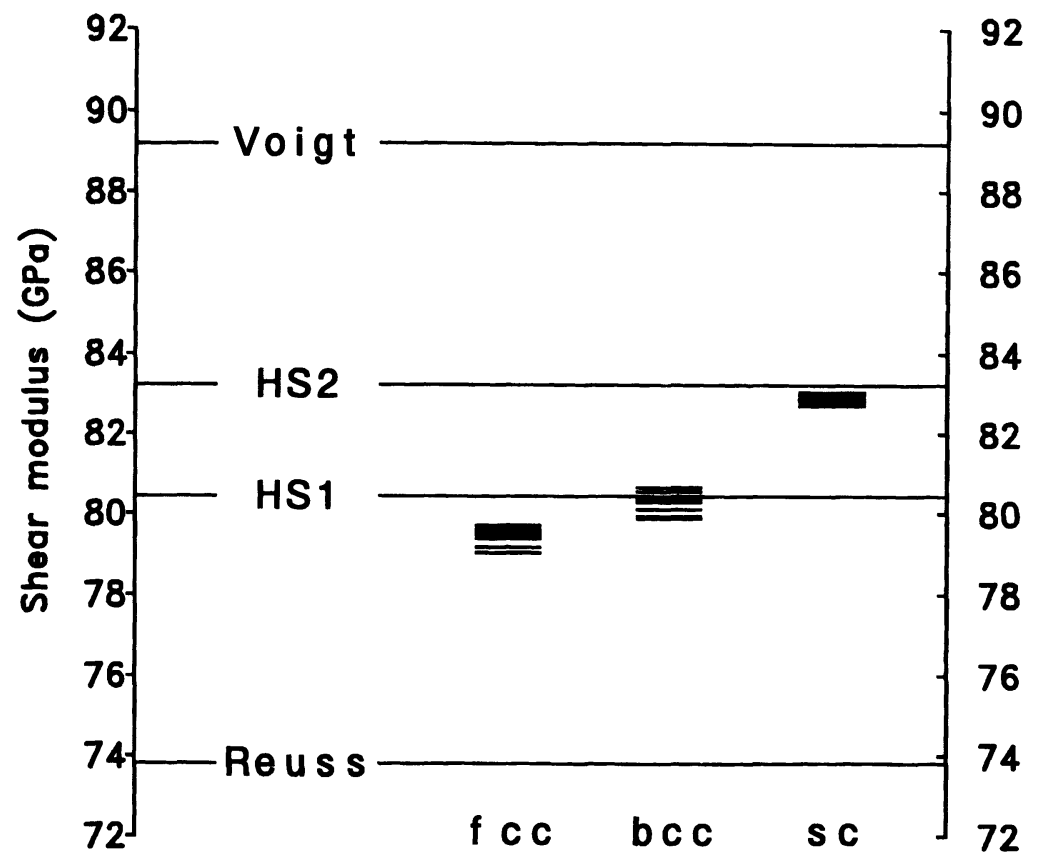

Figure 3 The elastic moduli of macroscopically isotropic iron in GPa. The situation is the same as in Figure 1. 
3(c)

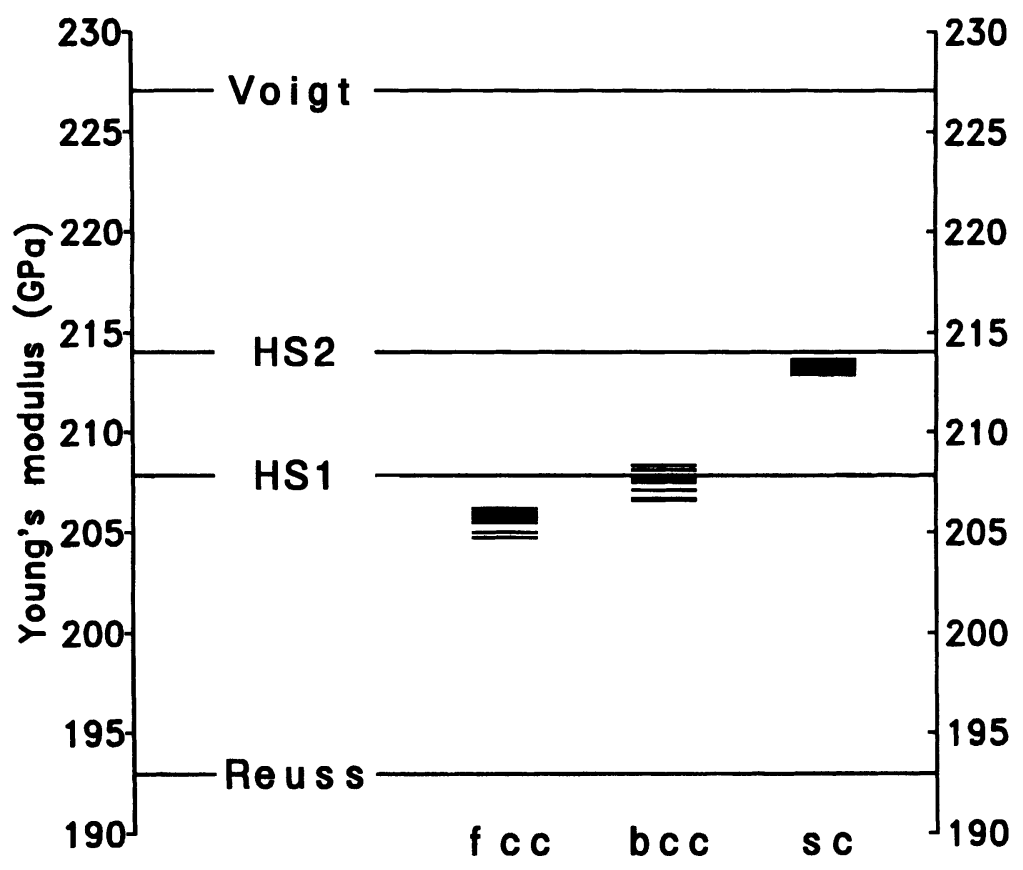

Figure 3 The elastic moduli of macroscopically isotropic iron in GPa. The situation is the same as in Figure 1.

4(a)

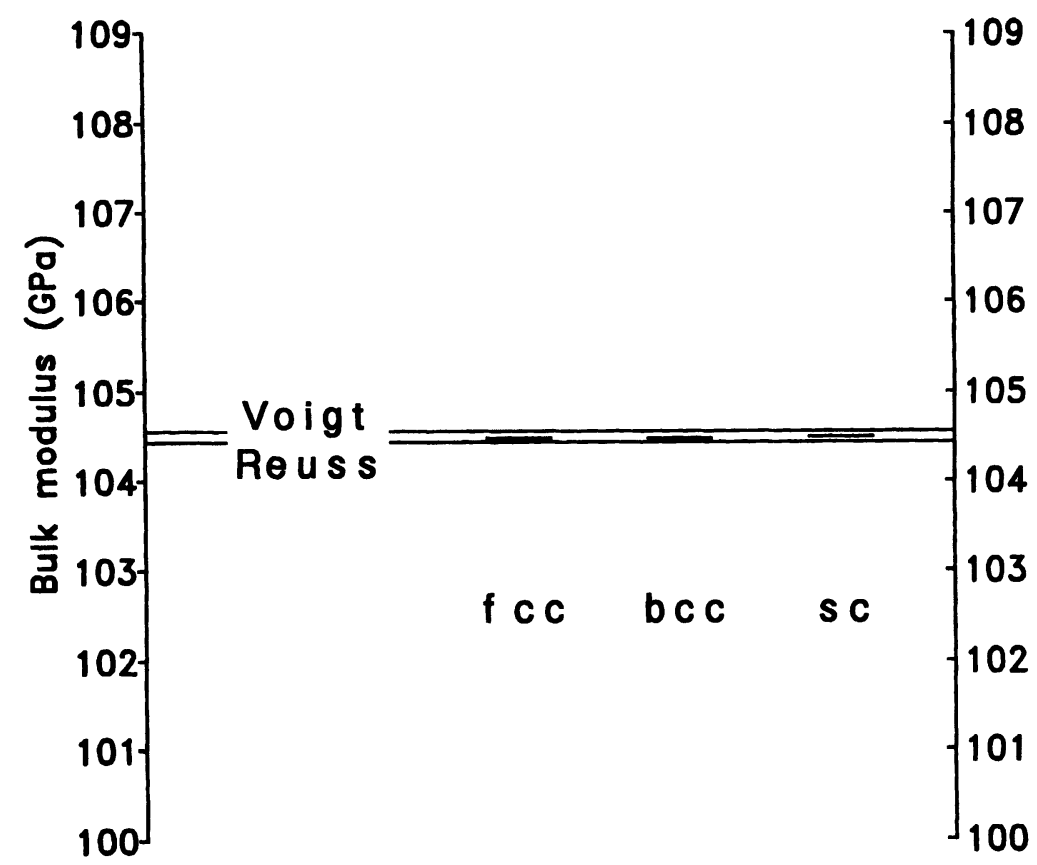

Figure 4 The elastic moduli of macroscopically isotropic titanium in GPa. The situation is the same as in Figure 1. 
4(b)

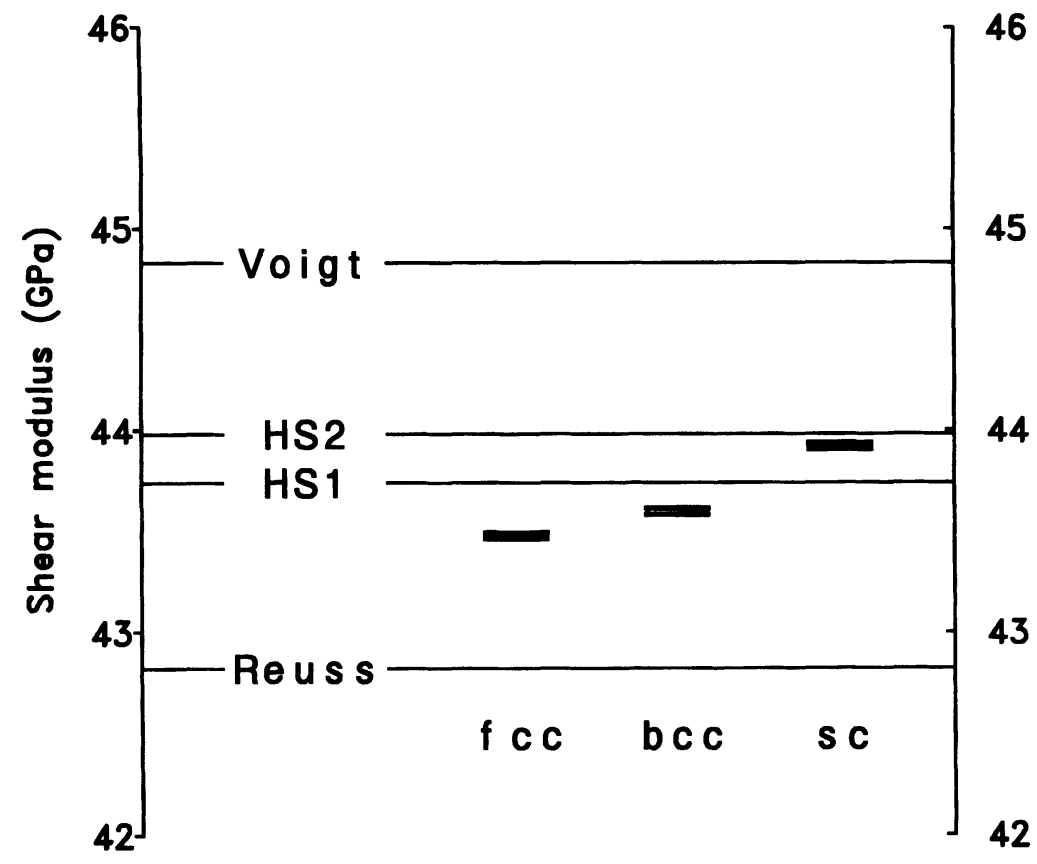

4(c)

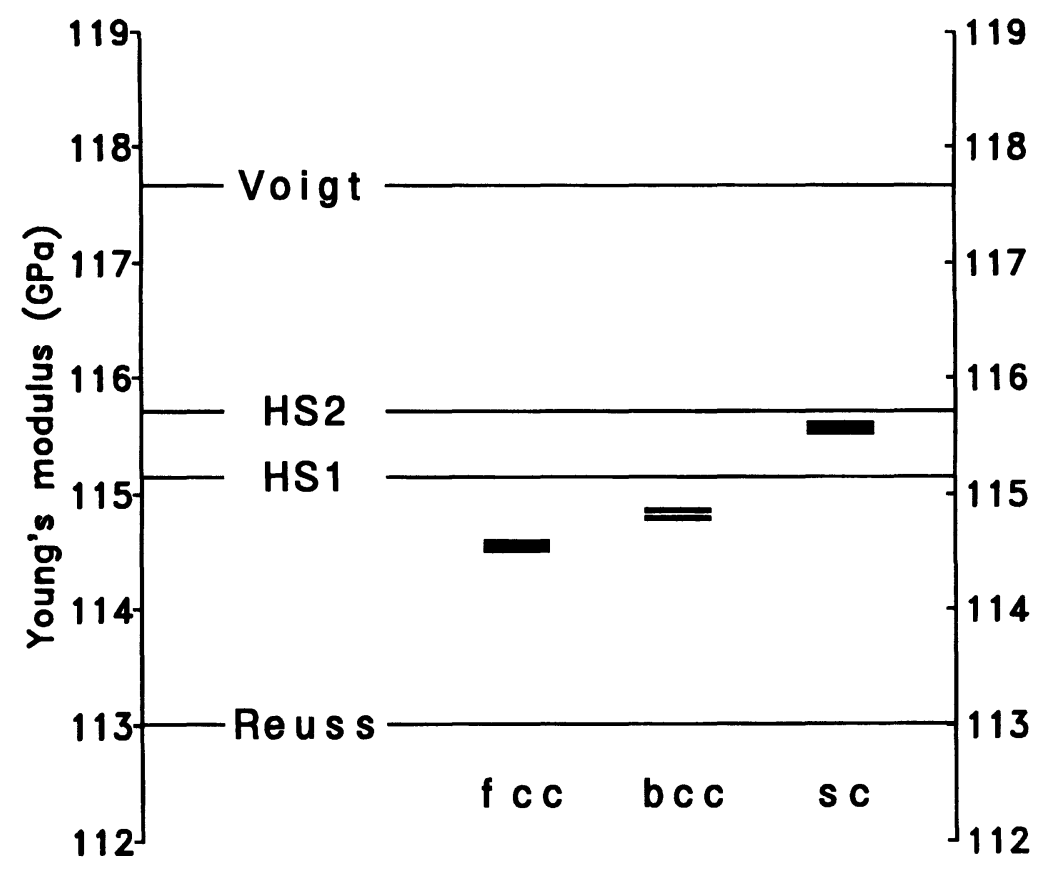

Figure 4 The elastic moduli of macroscopically isotropic titanium in GPa. The situation is the same as in Figure 1. 
5(a)

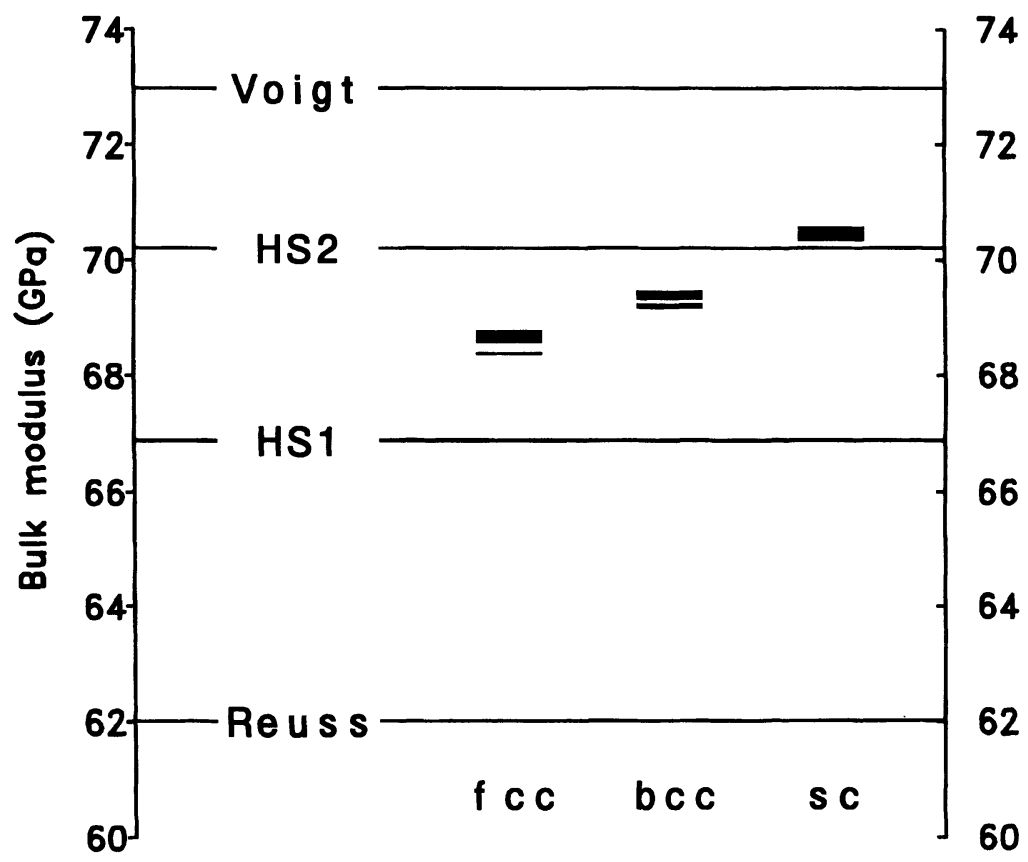

5(b)

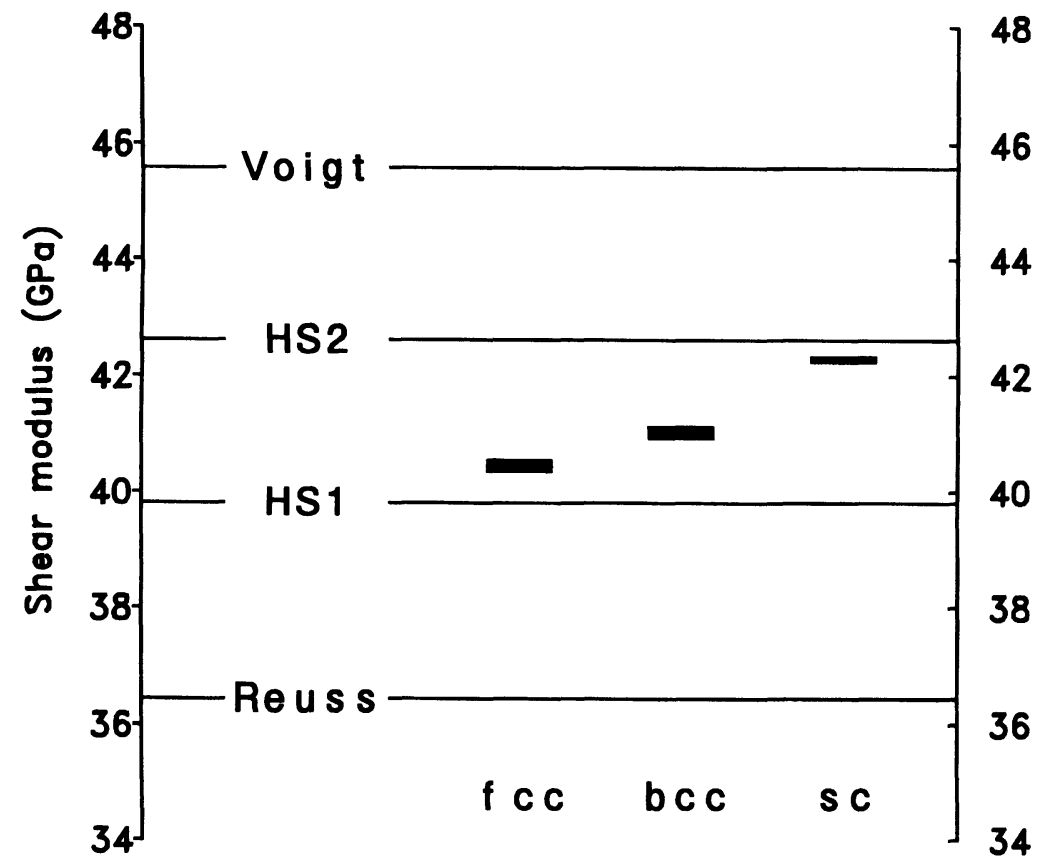

Figure 5 The elastic moduli of macroscopically isotropic zinc metal in GPa. The situation is the same as in Figure 1. 
$5(\mathrm{c})$

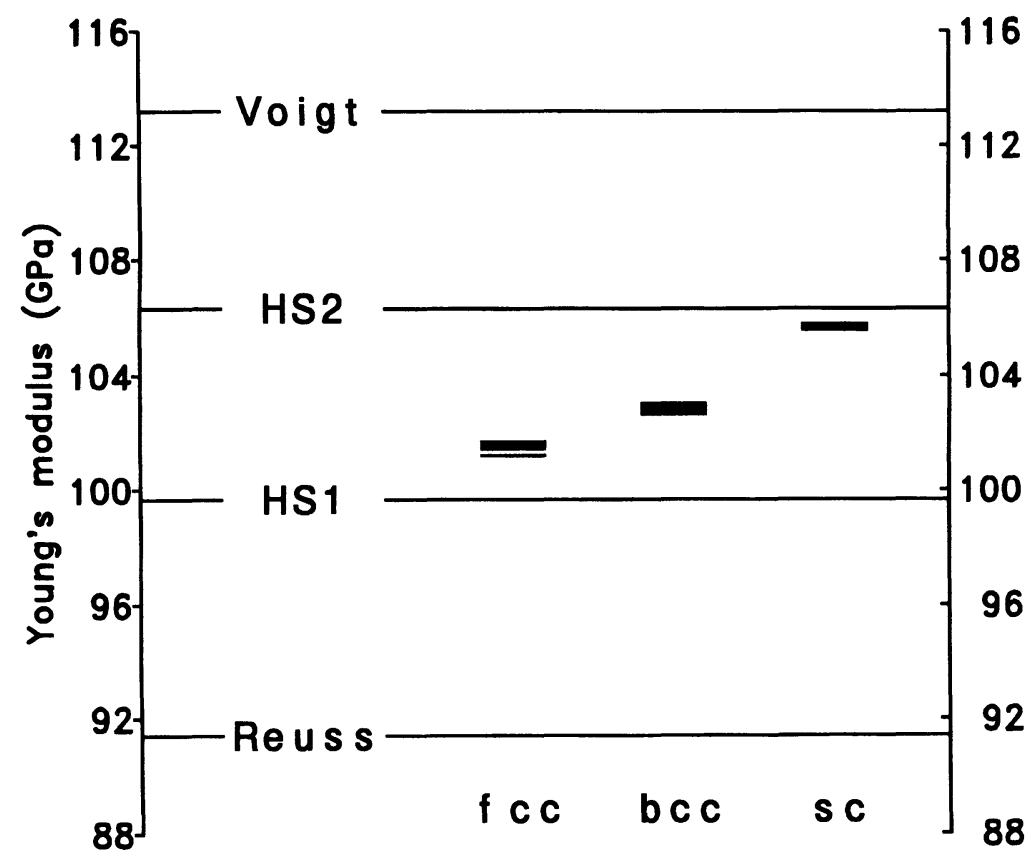

Figure 5 The elastic moduli of macroscopically isotropic zinc metal in GPa. The situation is the same as in Figure 1.

6(a)

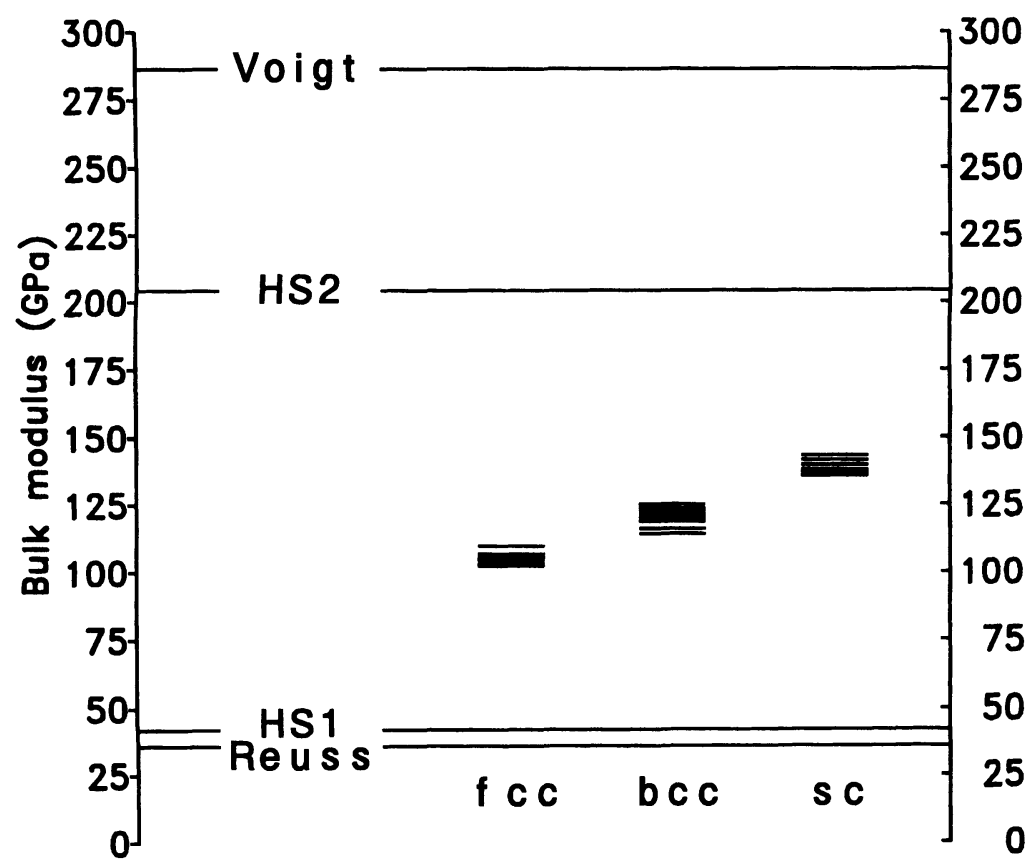

Figure 6 The elastic moduli of macroscopically isotropic graphite in GPa. The situation is the same as in Figure 1. 
6(b)

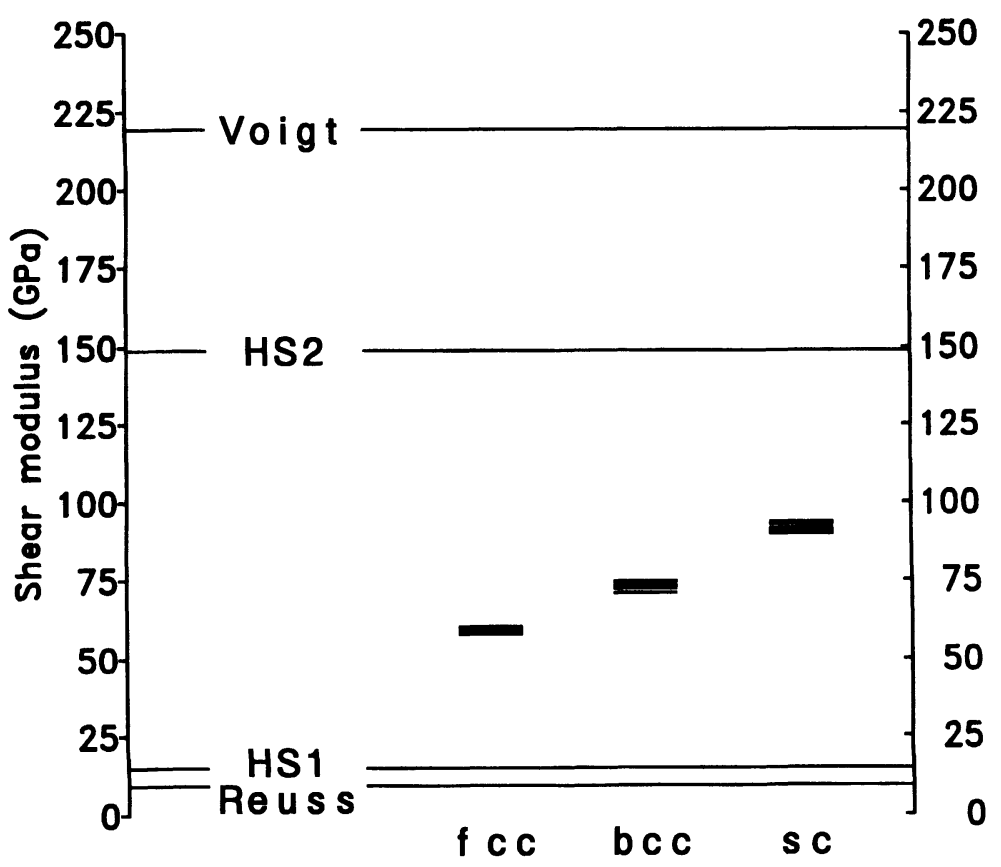

6(c)

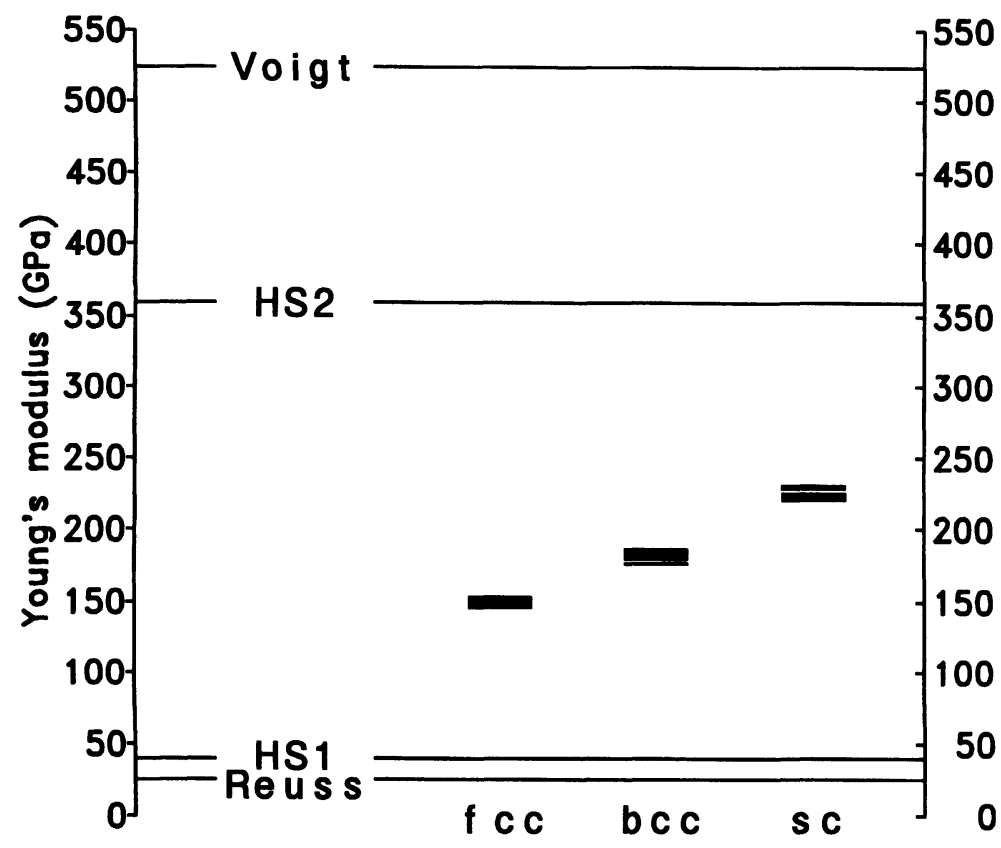

Figure 6 The elastic moduli of macroscopically isotropic graphite in GPa. The situation is the same as in Figure 1. 
7(a)

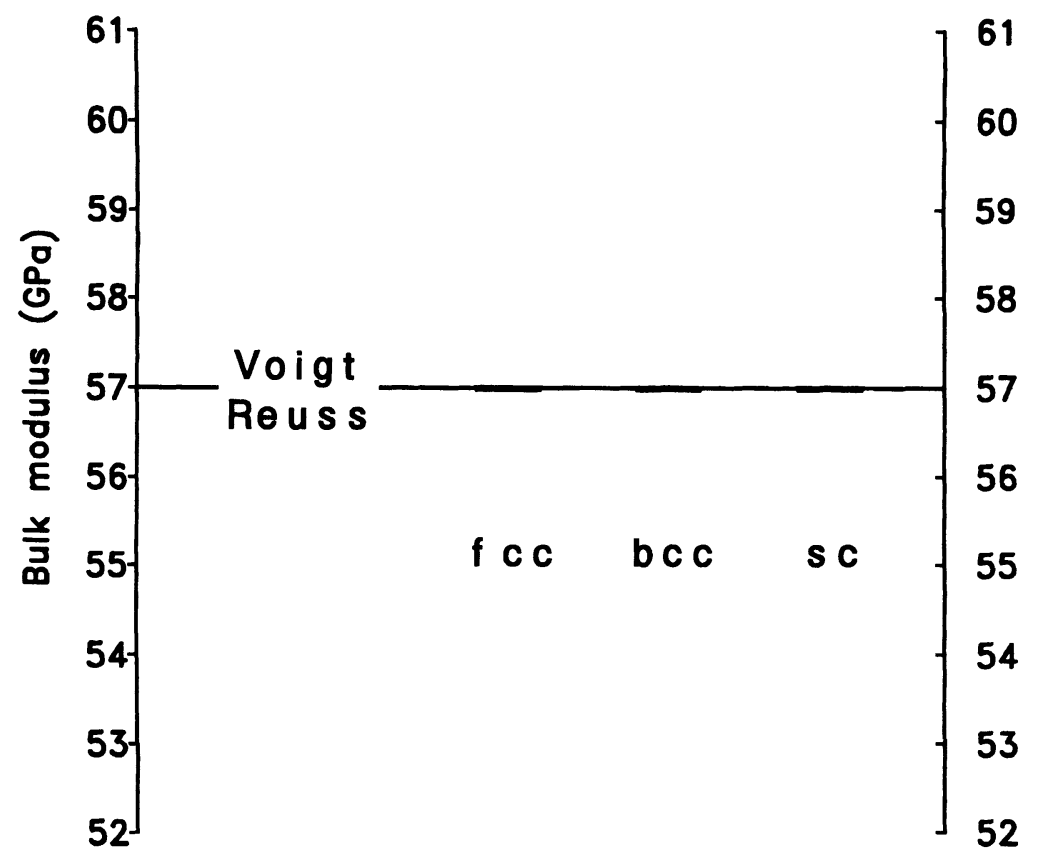

7(b)

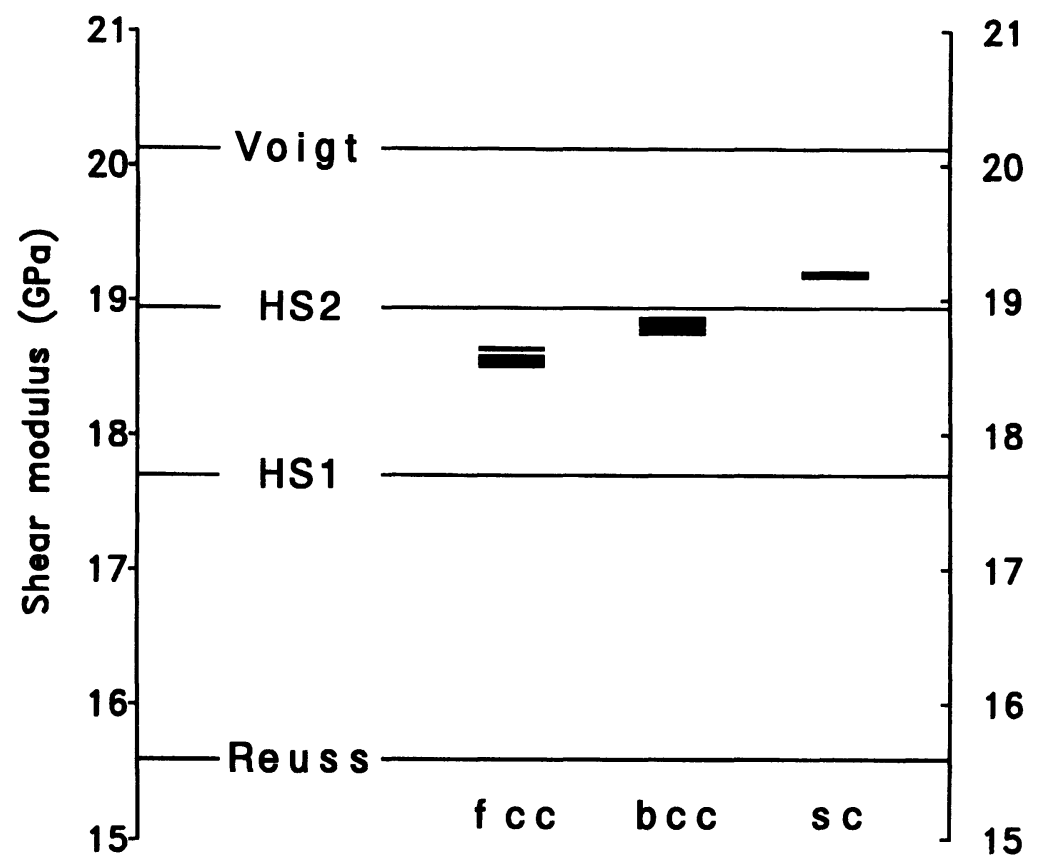

Figure 7 The elastic moduli of macroscopically isotropic tin metal in GPa. The situation is the same as in Figure 1. 
7(c)

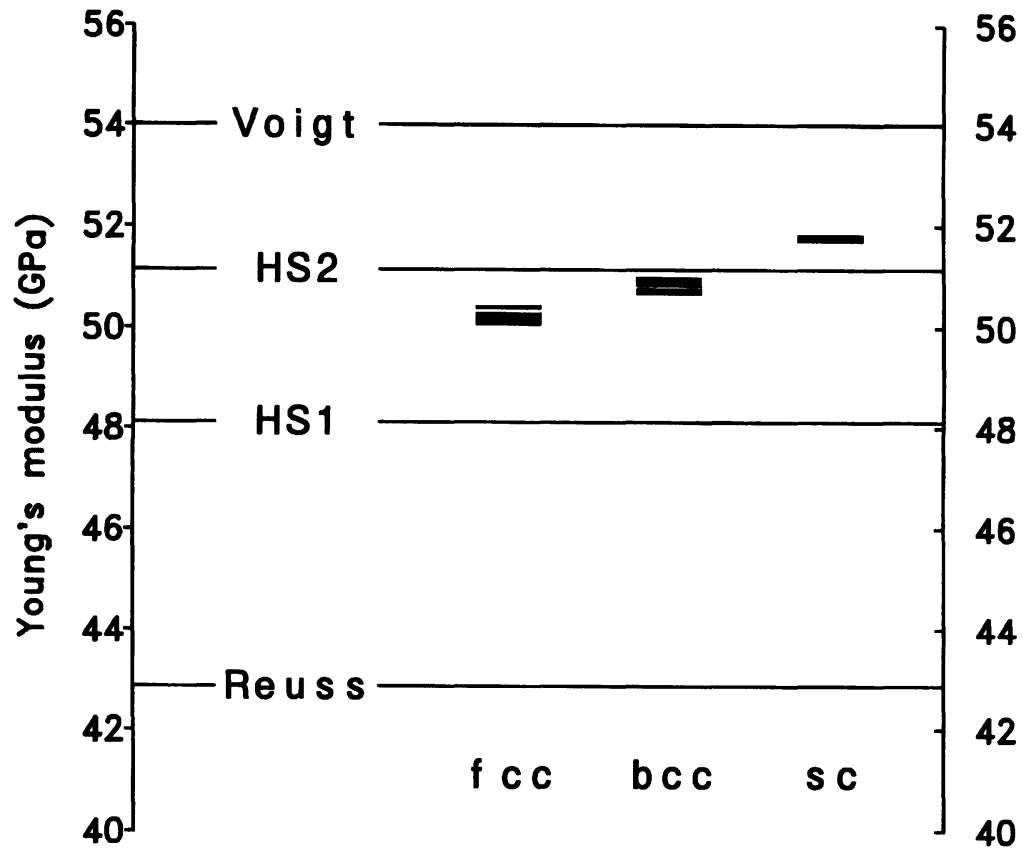

Figure 7 The elastic moduli of macroscopically isotropic tin metal in GPa. The situation is the same as in Figure 1.

Table 5 Results for the bulk modulus $B$ of polycrystalline materials in GPa. The columns HS1 and HS2 contain the values of Hashin and Shtrikman. The different grain shapes of the cluster method are labeled by the abbreviations fcc, bcc and sc (see text). For the cluster approach we have additionally listed the standard deviation of the moduli in GPa.

\begin{tabular}{|c|c|c|c|c|c|c|c|c|}
\hline & Reuss & HSI & Kröner & $f c c$ & $\begin{array}{c}\text { ister me } \\
\text { bcc }\end{array}$ & $s c$ & $H S 2$ & Voigt \\
\hline \multicolumn{9}{|l|}{ Cubic } \\
\hline $\mathrm{Ag}$ & 102.3 & 102.3 & 102.3 & $\begin{array}{r}102.3 \\
\pm 0.0\end{array}$ & $\begin{array}{r}102.3 \\
\pm 0.0\end{array}$ & $\begin{array}{l}102.3 \\
\pm 0.0\end{array}$ & 102.3 & 102.3 \\
\hline $\mathrm{Cu}$ & 137.6 & 137.6 & 137.6 & $\begin{array}{r}137.6 \\
\pm 0.0\end{array}$ & $\begin{array}{r}137.6 \\
\pm 0.0\end{array}$ & $\begin{array}{l}137.6 \\
\pm 0.0\end{array}$ & 137.6 & 137.6 \\
\hline $\mathrm{Fe}$ & 166.7 & 166.7 & 166.7 & $\begin{array}{r}166.7 \\
\pm 0.0\end{array}$ & $\begin{array}{l}166.7 \\
\pm 0.0\end{array}$ & $\begin{array}{r}166.7 \\
\pm 0.0\end{array}$ & 166.7 & 166.7 \\
\hline $\begin{array}{l}\text { Hexagonal } \\
\mathrm{Ti}\end{array}$ & 104.4 & 104.5 & 104.5 & $\begin{array}{r}104.5 \\
+\quad 0 .\end{array}$ & $\begin{array}{r}104.5 \\
+0 .\end{array}$ & $\begin{array}{r}104.5 \\
+0.0\end{array}$ & 104.5 & 104.6 \\
\hline $\mathrm{Zn}$ & 62.0 & 66.9 & 69.4 & $\begin{array}{r}68.6 \\
\pm 0.1\end{array}$ & $\begin{array}{r}69.3 \\
\pm 0.1\end{array}$ & $\begin{array}{r}70.4 \\
\pm 0.1\end{array}$ & 70.2 & 73.0 \\
\hline Graphite & 35.8 & 42.0 & 88.5 & $\begin{array}{r}104.9 \\
\pm 2.2\end{array}$ & $\begin{array}{r}120.1 \\
\pm 3.4\end{array}$ & $\begin{array}{r}138.4 \\
\pm 2.4\end{array}$ & 204.2 & 286.3 \\
\hline $\begin{array}{l}\text { Tetragonal } \\
\text { Sn }\end{array}$ & 57.0 & 57.0 & 57.0 & $\begin{array}{r}57.0 \\
\pm 0.0\end{array}$ & $\begin{array}{r}57.0 \\
\pm 0.0\end{array}$ & $\begin{array}{r}57.0 \\
\pm 0.0\end{array}$ & 57.0 & 57.0 \\
\hline
\end{tabular}


Table 6 Results for the shear modulus $G$ of polycrystalline materials in GPa. The columns HS1 and HS2 contain the values of Hashin and Shtrikman. The different grain shapes of the cluster method are labeled by the abbreviations fcc, bcc and sc (see text). For the cluster approach we have additionally listed the standard deviation of the moduli in GPa.

\begin{tabular}{|c|c|c|c|c|c|c|c|c|}
\hline & Reuss & HS1 & Kröner & $f c c$ & $\begin{array}{c}\text { ster met } \\
\text { bcc }\end{array}$ & $s c$ & $H S 2$ & Voig \\
\hline \multicolumn{9}{|l|}{ Cubic } \\
\hline $\mathrm{Ag}$ & 25.6 & 28.9 & 29.8 & $\begin{array}{r}29.3 \\
\pm 0.1\end{array}$ & $\begin{array}{r}29.9 \\
\pm 0.1\end{array}$ & $\begin{array}{r}30.7 \\
\pm 0.1\end{array}$ & 30.6 & 33.4 \\
\hline $\mathrm{Cu}$ & 40.1 & 46.1 & 48.3 & $\begin{array}{r}46.6 \\
\pm 0.2\end{array}$ & $\begin{array}{r}47.6 \\
\pm 0.2\end{array}$ & $\begin{array}{r}49.5 \\
\pm 0.1\end{array}$ & 49.5 & 54.7 \\
\hline $\mathrm{Fe}$ & 73.8 & 80.4 & 81.6 & $\begin{array}{r}79.4 \\
\pm 0.2\end{array}$ & $\begin{array}{r}80.3 \\
\pm 0.3\end{array}$ & $\begin{array}{r}82.9 \\
\pm 0.1\end{array}$ & 83.2 & 89.2 \\
\hline $\begin{array}{l}\text { Hexagonal } \\
\mathrm{Ti}\end{array}$ & 42.8 & 43.7 & 43.8 & $\begin{array}{r}43.5 \\
\pm 0.0\end{array}$ & $\begin{array}{r}43.6 \\
\pm 0.0\end{array}$ & $\begin{array}{r}43.9 \\
\pm 0.0\end{array}$ & 44.1 & 44.8 \\
\hline $\mathrm{Zn}$ & 36.4 & 39.8 & 41.9 & $\begin{array}{r}40.5 \\
+0.1\end{array}$ & $\begin{array}{r}41.0 \\
\pm 0.1\end{array}$ & $\begin{array}{r}42.3 \\
\pm 0.0\end{array}$ & 42.6 & 45.6 \\
\hline Graphite & 9.21 & 14.9 & 53.3 & $\begin{array}{r}58.9 \\
\pm 0.9\end{array}$ & $\begin{array}{r}73.0 \\
+\quad 1.1\end{array}$ & $\begin{array}{r}91.3 \\
\pm \quad 1.2\end{array}$ & 148.9 & 219.4 \\
\hline $\begin{array}{l}\text { Tetragonal } \\
\text { Sn }\end{array}$ & 15.6 & 17.7 & 18.7 & $\begin{array}{r}18.6 \\
\pm 0.1\end{array}$ & $\begin{array}{r}18.8 \\
\pm 0.0\end{array}$ & $\begin{array}{r}19.2 \\
\pm 0.0\end{array}$ & 19.0 & 20.1 \\
\hline
\end{tabular}

Table 7 Results for Young's modulus $E$ of polycrystalline materials in GPa. The columns HS1 and HS2 contain the values of Hashin and Shtrikman. The different grain shapes of the cluster method are labeled by the abbreviations fcc, bcc and sc (see text). For the cluster approach we have additionally listed the standard deviation of the moduli in GPa.

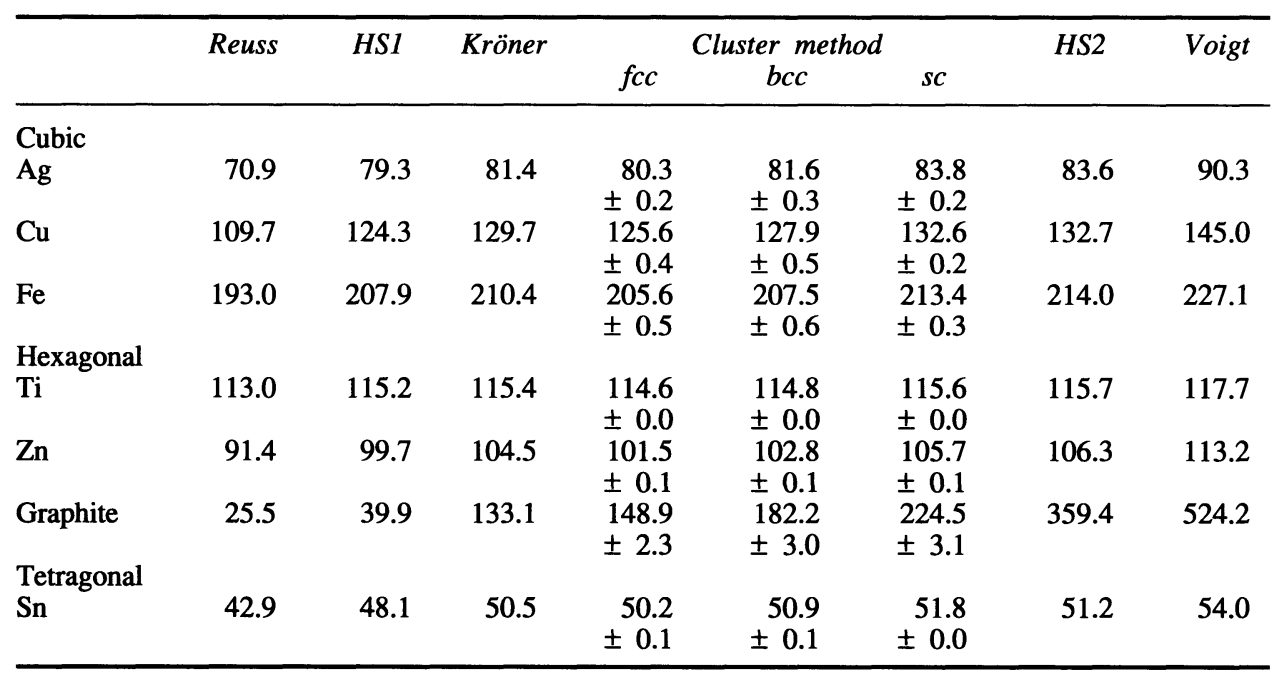


For materials with an anisotropy in the order of 2 to 4 (see Table 4), like silver, copper, iron, zinc and tin, the effect of the grain shape on the elastic constants amounts up to $6 \%$. For example, the difference between sc- and fcc-shear modulus for copper is about $6 \%$ of the average of these both values. Materials whose anisotropy is less than 1.5, like titanium, show only a negligible influence of the grain shape on the properties of the polycrystalline substance $(<1 \%)$. For the extremely anisotropic graphite the effect is in the range of 25 to $45 \%$. In this case it is essential for reliable calculations to take the exact grain shape into consideration. Without detailed information about the microstructure of polycrystalline graphite it is impossible to give even an approximate value for the effective constants of this material.

For the investigated 7 materials the values for the fcc-clusters are always smaller than those for the bcc-clusters which are in their turn smaller than those for the scclusters. This fact leads to the fundamental conclusion that with increasing coordination number of the cluster the elastic moduli decrease.

\section{CONCLUSIONS}

The results of the present paper show that the cluster method is a suitable tool to resolve the effect of the grain shape on the effective elastic constants of polycrystalline materials. The single crystal anisotropies $A_{G}$ and $A_{E}$ yield a criterion to estimate the order of this effect. For materials with small single crystal anisotropy, i.e. $A_{G} \approx A_{E}<2$, the effect is negligible. If the anisotropy lies between 2 and 4 , like for copper or iron the influence of the grain shape becomes noticeable. Graphite is an example with extremely high anisotropy. In this case calculating effective elastic constants without including the grain shape seems to be useless. For all investigated materials the elastic moduli decrease with increasing coordination number.

\section{Acknowledgement}

The present work was financially supported by the Deutsche Forschungsgemeinschaft which is gratefully acknowledged.

\section{References}

Bradfield, G. (1962). Private communication to Kneer, G. (quoted in (Kneer, 1965)).

Hashin, Z. and Shtrikman, S. (1962a). On some variational principles in anisotropic and nonhomogeneous elasticity, J. Mech. Phys. Solids 10, 335.

Hashin, Z. and Shtrikman, S. (1962b). A variational approach to the theory of the elastic behaviour of polycrystals, J. Mech. Phys. Solids 10, 343.

Hill, R. (1952). The elastic behaviour of a crystalline aggregate, Proc. Phys. Soc. A 65, 351.

Kiewel, H. and Fritsche, L. (1994a). Calculation of average elastic moduli of polycrystalline materials including $\mathrm{BaTiO}_{3}$ and high- $\mathrm{T}_{\mathrm{C}}$ superconductors, Proc. ICOTOM-10, Materials Science Forum 157162, 1609.

Kiewel, H. and Fritsche, L. (1994b). Calculation of effective elastic moduli of polycrystalline materials including non textured samples and fiber textures, Phys. Rev. B 50, 5.

Kneer, G. (1964). Zur Elastizität vielkristalliner Aggregate mit und ohne Textur, Doctoral Thesis, Technische Universität Clausthal.

Kneer, G. (1965). Über die Berechnung der Elastizitätsmoduln vielkristalliner Aggregate mit Textur, phys. stat. sol. 9, 825 . 
Kröner, E. (1958). Berechnung der elastischen Konstanten des Vielkristalls aus den Konstanten der Einkristalle, Z. Phys. 151, 504.

Kröner, E. (1977). Bounds for effective elastic moduli of disordered materials, J. Mech. Phys. Solids 25, 137.

Landolt-Börnstein (1979). Elastic, Piezoelectric and Related Constants, Group III of New Series Vol. 11, Springer, Heidelberg.

Reuss, A. (1929). Berechnung der Fließgrenze von Mischkristallen auf Grund der Plastizitätsbedingung für Einkristalle, Z. Angew. Math. Mech. 9, 49.

Voigt, W. (1910). Lehrbuch der Kristallphysik, Teubner, Berlin.

Zeller, R. and Dederichs, P. H. (1973). Elastic Constants of Polycrystals, phys. stat. sol. (b) 55, 831. 